\title{
Research progress of monitoring, forecasting, and prevention of rockburst in underground coal mining in China
}

\author{
Linming Dou $\cdot$ Zonglong Mu $\cdot$ Zhenlei Li $\cdot$ Anye Cao $\cdot$ Siyuan Gong
}

Received: 20 November 2013/Revised: 24 May 2014/Accepted: 25 May 2014/Published online: 11 November 2014

(C) The Author(s) 2014. This article is published with open access at Springerlink.com

\begin{abstract}
As one of the dynamic disasters of coal mines, rockburst seriously affects underground safe coal mining. Based on the laboratory test, field test, and theoretical analysis, this study proposed the principle of the rock burst induced by the combination of dynamic and static stresses and divided such rock burst into three types, including induced by primary dynamic stress, mainly induced by dynamic stress, and by dynamic stress in low critical stress state. The expressions of the static stress induced by coal mining and dynamic stress induced by mining tremors were obtained. Moreover, theories and technologies at home and abroad were summarized concerning the monitoring, forecasting, and preventing of rockburst. These mainly include the zoning and leveling forecasting method, electromagnetic radiation technology, elastic wave and seismic wave computed tomography technologies in aspect of rockburst monitoring, as well as the intensity weakening theory, the strong-soft-strong structure effect, the directional hydraulic fracturing technology, the roadway support system in regards of rockburst prevention. The prospect of rockburst development suggested that researches concerning the rockburst mechanism should be quantitatively developed around the roadway and coalface surrounding coal-rock mass. It should be focused on the rockburst mechanism and prevention technology of mining with over 1,000 km deep and mining in large tectonic zone. In addition, the monitoring and prevention of rockburst should be based on rockburst mechanism.
\end{abstract}

Keywords Rockburst - Dynamic stress $\cdot$ Static stress $\cdot$ Mining tremor $\cdot$ Monitoring and forecasting $\cdot$ Prevention

\section{Introduction}

With the increase of mining depth and intensity, rockburst has become a common safety problem for underground coal mines (Dou and He 2001; Brady and Brown 2004). It is a sudden engineering disaster caused by the dynamic evolution of the deformation and facture of coal-rock mass. Studies concerning the mechanism, monitoring, and prevention of rockburst show that it is a worldwide problem

L. Dou $\cdot$ Z. Mu $\cdot$ Z. Li $\cdot$ A. Cao $\cdot$ S. Gong

State Key Laboratory of Coal Resources and Safe Mining, China

University of Mining and Technology, Xuzhou 221116, China

L. Dou $\cdot$ Z. Mu $(\bowtie) \cdot$ Z. Li $\cdot$ A. Cao

School of Mines, China University of Mining and Technology,

Xuzhou 221116, China

e-mail: muzonglong@163.com; lmdou@cumt.edu.cn and also a technical problem that needs to be solved urgently.

Researchers around the world have developed a lot of studies and proposed a variety of hypotheses on the dynamic disaster mechanism of coal-rock mass according to tests and theoretical analysis, such as energy theory (Cook 1965), stiffness theory (Petukhov and Linko 1979), strength theory ( $\mathrm{Li}$ 1985), rockburst tendency theory (Kidybiński 1981), three-criteria theory, system deformation instability theory (Zhang 1987), etc. These hypotheses indicate the occurrence condition and mechanism of rockburst from different aspects. However, each theory has its own characteristics and limitations. Especially in recent years, serious rockburst also happened in some coal seams without rockburst tendency or with low original stresses and shallow-burying. For example, the rockburst in $\mathrm{Ku}$ angou Coal Mine in China in October 8, 2010 (at mining depth of $317 \mathrm{~m}$ ) resulted in many casualties. In addition, 
experimental study (Singh 1988) also signified that the mechanical parameters of coal/rock was greatly influenced by the loading rate. During dynamic load tests, soft coal showed a great strength improvement and a similar dynamic failure mode with hard coal. Analysis (Gu et al. 2012) on causes for the rockburst in field implied that most of the rockbursts were related to the dynamic disturbances induced by mining or blasting.

In recent years, rockburst research teams of the present study explored the principle of the rockburst induced by static and dynamic stresses superposition to explain rockburst and guide the monitoring and management on the rockburst. Moreover, they profoundly investigated the zoning and leveling forecasting method in aspect of rockburst monitoring, as well as the intensity weakening theory, the strong-soft-strong structure effect in aspect of rockburst prevention. Moreover, they improved the roadway support system and developed the electromagnetic radiation (EMR) technology, the elastic wave computed tomography (CT) technology, the seismic wave CT technology, and the high-pressure directional hydraulic fracturing technology, which could conduct effective forecasting and controlling of rockburst. Basing on the summary of the theories and technologies above and the analysis of existing researches (Ju and Pan 2012; Pan et al. 2013) on the routine monitoring and controlling technologies of rockburst in Chinese coal mines, this study made prospects for the future development of rockburst monitoring and prevention.

\section{Principle of rockburst induced by static and dynamic stresses superposition}

\subsection{Proposing of the model}

According to energy criteria, rockburst is a dynamic phenomenon generated when the energy released by the failure of the mechanical equilibrium state of the surrounding coal-rock mass exceeds the energy consumed. It is expressed as:

$\frac{\mathrm{d} U}{\mathrm{~d} t}=\frac{\mathrm{d} U_{\mathrm{R}}}{\mathrm{d} t}+\frac{\mathrm{d} U_{\mathrm{C}}}{\mathrm{d} t}+\frac{\mathrm{d} U_{\mathrm{S}}}{\mathrm{d} t}>\frac{\mathrm{d} U_{\mathrm{b}}}{\mathrm{d} t}$

where, $U_{\mathrm{R}}$ is the energy accumulated in surrounding rocks; $U_{\mathrm{C}}$ is the energy accumulated in coal seams; $U_{\mathrm{S}}$ is the energy released by mining tremors; $U_{\mathrm{b}}$ is the energy consumed by rockburst. The sum of the coal-rock mass accumulated energy and the mining tremor induced energy is expressed as.

$U=\frac{\left(\sigma_{\mathrm{s}}+\sigma_{\mathrm{d}}\right)^{2}}{2 E}$

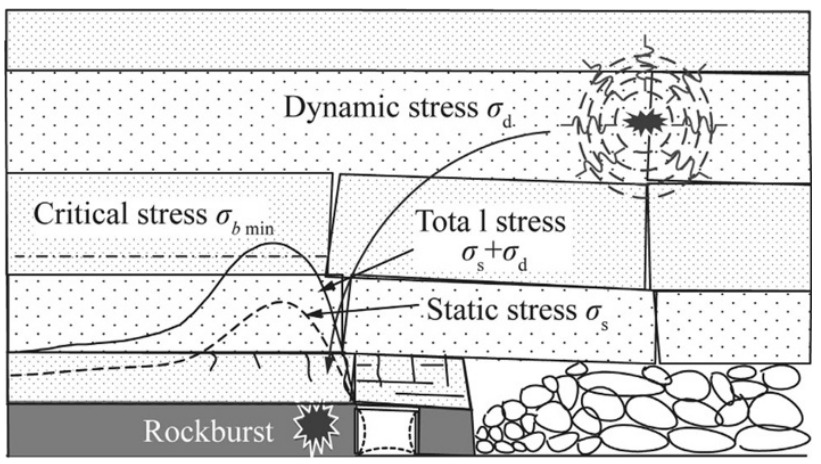

Fig. 1 Sketch showing the principle of the rockburst induced by static and dynamic stresses superposition

where, $\sigma_{\mathrm{s}}$ refers to the static stress in the coal-rock mass; $\sigma_{\mathrm{d}}$ denotes to the dynamic stress induced by mining tremors.

The minimum energy consumed by rockburst is calculated by:

$U_{b \min }=\frac{\sigma_{b \min }^{2}}{2 E}$

where, $\sigma_{b \min }$ is the minimum stress when rockburst happens.

Therefore, the occurrence of rockburst should meet the following equation, namely:

$\sigma_{\mathrm{s}}+\sigma_{\mathrm{d}} \geq \sigma_{b \min }$

Equation (4) indicates that rockburst is prone to being induced in case of the total stress (due to superposition of static stress in the coal and dynamic stress induced by tremors) exceeding the critical stress. This is the principle of the rockburst induced by static and dynamic stresses superposition, as shown in Fig. 1.

\subsection{Model analysis and discussion}

\subsubsection{Static stress}

Generally, the static stress within the coal-rock mass around mining area is composed of ground pressure and abutment pressure, namely,

$\sigma_{\mathrm{s}}=\sigma_{\mathrm{s} 1}+\sigma_{\mathrm{s} 2}=(k+\lambda) \gamma H$

where, $\gamma$ is the volume weight of the overlying strata; $H$ is the thickness of the overlying strata; $\lambda$ is the horizontal stress coefficient; $k$ is the concentration coefficient of the abutment stress.

Ground pressure consists of gravity stress and tectonic stress:

$\sigma_{\mathrm{s} 1}=\gamma H+\lambda \gamma H=(1+\lambda) \gamma H$

Abutment stress is expressed as:

$\sigma_{\mathrm{s} 2}=(k-1) \gamma H$ 
In particular, when mining approaches to faults, the rockburst induced by fault slipping takes a dominant position. In this condition, the whole coal-rock system and the faults are treated as a whole. The static stress should be the Coulomb stress on the fault surface.

$\sigma_{\mathrm{s}}=\Delta C F S=\Delta \tau+\mu(\Delta \sigma-B \Delta P)$

where $\Delta \tau$ denote changes in shear and normal stresses resolved on a fault plane, $\mu$ is the coefficient of friction, $\Delta P$ is the change in isotropic compressional stress, and $B$ is similar to Skempton's coefficient.

\subsubsection{Dynamic stress}

The dynamic stress during mining mainly originated from the mining activities and the stress response of coal-rock to mining activities, which is specifically represented as the coal-cutting by shearer, the moving of hydraulic supports, mechanical shock, blasting, roof and floor breaking, coal body instability, gas outburst, coal bump, and fault slip etc. These dynamic stress origins are all called as mining tremor.

In assumption of the coal-rock mass being isotropic continuous medium, the dynamic stress yielded by stress wave in the coal-rock can be expressed as:

$\left\{\begin{aligned} \sigma_{\mathrm{dP}} & =\rho v_{\mathrm{P}}\left(v_{p p}\right)_{\mathrm{P}} \\ \tau_{\mathrm{dS}} & =\rho v_{\mathrm{S}}\left(v_{p p}\right)_{\mathrm{S}}\end{aligned}\right.$

where, $\sigma_{\mathrm{dP}}$ and $\tau_{\mathrm{dS}}$ are dynamic stresses yielded by $\mathrm{P}$ wave and $\mathrm{S}$ wave respectively; $\rho$ is the density of the coal-rock medium; $v_{\mathrm{P}}$ and $v_{\mathrm{S}}$ are the propagation velocity of $\mathrm{P}$ wave and $\mathrm{S}$ wave respectively; $\left(v_{p p}\right)_{\mathrm{P}}$ and $\left(v_{p p}\right)_{\mathrm{S}}$ are the peaked vibration velocity of a mass point induced by the propagation of $\mathrm{P}$ wave and $\mathrm{S}$ wave respectively.

\subsubsection{Conditions for rockburst}

The effects of the superposition of tremors' dynamic disturbance with static stress on rockburst are mainly manifested as following three situations:

(1) High static stress $\left(\sigma_{\mathrm{s}}\right)$. During deep mining, the coalrock mass around roadways and coalfaces presents high original stress. Moreover, the roadway excavation or coalface retreating results in the high stress concentration. In this condition, the stress level has not reached the critical stress state inducing the dynamic failure of coal-rock. However, under the minor dynamic stress increment caused by far-field mine tremor, the total stress field formed by the dynamic and static stresses superposition exceeds the critical stress level and thus a rockburst occurs. In this case, the dynamic stress induced by mine tremor plays an inducing role in the coal rock failure. This is the most common form in deep mining.

(2) High dynamic stress $\left(\sigma_{\mathrm{d}}\right)$. During shallow mining, the coal-rock mass around roadways and coalfaces presents low original stress. However, due to the high energy released by far-field mine tremor, the dynamic stress converted from the tremor source to the coal mass show high instantaneous increment. Thus, the total stress may also exceed the critical stress level of dynamic failure. Therefore, coal masses develop sudden dynamic failure. In addition, researches (He 2013) prove that, coal rocks exhibit higher burst tendency under high loading rate than that under normal state. Moreover, the coal rocks that are originally identified as no burst tendency may also show burst failure given high loading rate or dynamic load. Here, the instantaneous dynamic disturbance of mine tremor plays a dominant role in the burst failure process. This is why the rockburst may also be observed in the shallow mining process or the coal rocks without burst tendency originally identified.

(3) Low critical value $\left(\sigma_{b \min }\right)$. Due to the nonuniformity and the physical-mechanical property differences of coal rocks, the critical stress levels in different regions are different when rockburst happens. In case of the low static stress in coal rock and the low dynamic stress triggered by mine tremor, while the physical-mechanical properties of the surrounding coal rocks change suddenly, rockburst may also be caused. This happens when the critical stress level for rockburst suddenly reduces to a level being smaller than the superposed total stress. For example, during the mining activities around the fault, the stress on the fault surface lies in a critical balance state. The rockburst is mainly induced by fault slip, specifically, by the local adjustment of the stress field, or the passing through of the seismic wave of mine tremor.

\subsubsection{Monitoring methods for static and dynamic stresses}

The principle of rockburst induced by static and dynamic stresses superposition suggests that the rockburst is mainly caused by combination effects of dynamic and static stresses. Therefore, the monitoring and forecasting of rockburst guided by this theory should be mainly focused on the two aspects. The monitoring methods for dynamic and static stresses are as follows:

Dynamic stress is mainly monitored through the breaking law of coal rocks. Thus, microseismic method and seismic wave CT technology can be used to monitor the whole coal 


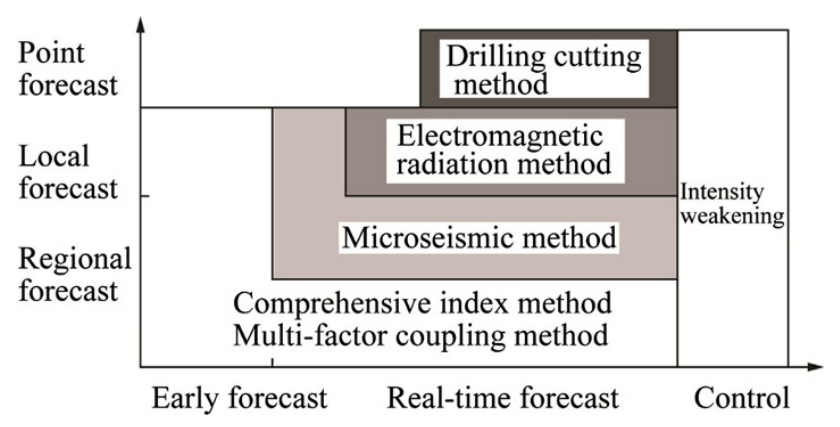

Fig. 2 The zoning spatio-temporal forecast of rockburst danger

mine as well as the coalface. Or, the EMR technology and the earth-sound technology can be used to monitor the coalface. Static stress monitoring mainly focuses on the stress distribution around the longwall panel through coal stress monitoring, drilling cutting monitoring, and elastic wave CT test, etc.

\section{Monitoring and forecasting of rockburst}

\subsection{Zoning and leveling forecasting}

At present, the zoning and leveling forecasting method has been widely used in coal mines with rockburst danger and has achieved stratifying achievements. This method was proposed by Dou and He (2007), as shown in Fig. 2 and Table 1. In time sense, the forecasting of rockburst includes early comprehensive analysis forecast and real-time forecast. The former mainly adopts the comprehensive index method and the multi-factor coupling method, while the latter mainly uses the EMR method, the microseismic method, and the drilling cutting method etc. In space sense, the forecasting of rockburst mainly includes regional forecast, local forecast, and point forecast. Regional forecast mainly uses the comprehensive index method, the multi-factor coupling method, and microseismic method. Local forecast mainly employs the comprehensive index method, the multi-factor coupling method, the microseismic method, and the EMR method. Point forecast uses the drilling cutting method.

Rockburst was forecasted on four danger degrees, namely no burst danger, weak burst danger, medium burst danger, and intensive burst danger. It is demanded to comprehensively determine the burst danger degree and to process the dangerous regions and locations using intensity weakening technology.

\subsection{Elastic wave CT technology to detect local static stress distribution}

Elastic wave CT technology is also called as active CT technology since the tremor source is stimulated artificially and the location of the tremor source is known. Researcher
Table 1 The leveling forecast of rockburst danger

\begin{tabular}{|c|c|c|c|}
\hline $\begin{array}{l}\text { Danger } \\
\text { degree }\end{array}$ & $\begin{array}{l}\text { Danger } \\
\text { state }\end{array}$ & $\begin{array}{l}\text { Comprehensive } \\
\text { index }\end{array}$ & Controlling measures \\
\hline A & No & $<0.25$ & $\begin{array}{l}\text { Managing the mining area } \\
\text { normally and conducting } \\
\text { the design and mining the } \\
\text { same as that without } \\
\text { rockburst danger }\end{array}$ \\
\hline $\mathrm{B}$ & Weak & $0.25-0.5$ & $\begin{array}{l}\text { Providing monitoring and } \\
\text { pressure releasing } \\
\text { equipment. Formulating } \\
\text { monitoring and controlling } \\
\text { plans. Conducting } \\
\text { monitoring and pressure- } \\
\text { releasing measures and } \\
\text { checking their validity }\end{array}$ \\
\hline $\mathrm{C}$ & Medium & $0.5-0.75$ & $\begin{array}{l}\text { In addition to the measures } \\
\text { taken as weak danger, } \\
\text { reasonably allocating } \\
\text { roadways and chambers, } \\
\text { reasonably selecting } \\
\text { mining and supporting } \\
\text { parameter etc., limiting } \\
\text { miners' number, } \\
\text { determining disaster- } \\
\text { avioding route, conducting } \\
\text { pre-mining pressure- } \\
\text { releasing measures }\end{array}$ \\
\hline D & Strong & $>0.75$ & $\begin{array}{l}\text { In addition to the measures } \\
\text { taken as medium danger, } \\
\text { pre-mining pressure- } \\
\text { releasing measures should } \\
\text { be conducted } \\
\text { comprehensively and the } \\
\text { validity should be checked } \\
\text { comprehensively. Mining } \\
\text { activities are conducted in } \\
\text { case that rockburst danger } \\
\text { is eliminated. If rockburst } \\
\text { danger is not (or cannot be) } \\
\text { eliminated, mining } \\
\text { activities should be } \\
\text { terminated or be re- } \\
\text { designed }\end{array}$ \\
\hline
\end{tabular}

concerning this technology was initiated early in countries out of China. China began to apply the elastic wave CT technology to mining geology in 1986 (Wang et al. 1996) to detect the geologic anomalies such as collapse column, scouring zone, gas enrichment area, fault, gob area of old mine, and igneous rock etc. The data acquisition system of this technology is mainly an explosion-proof digital seismograph. Researches in recent years have been focusing on application of elastic wave CT technology to the forecast of rockburst and have got certain achievements. The application of this technology in the rockburst forecast is based on the recognition on the close correlation between the occurrence of rockburst and the stress state in coal rocks, as 


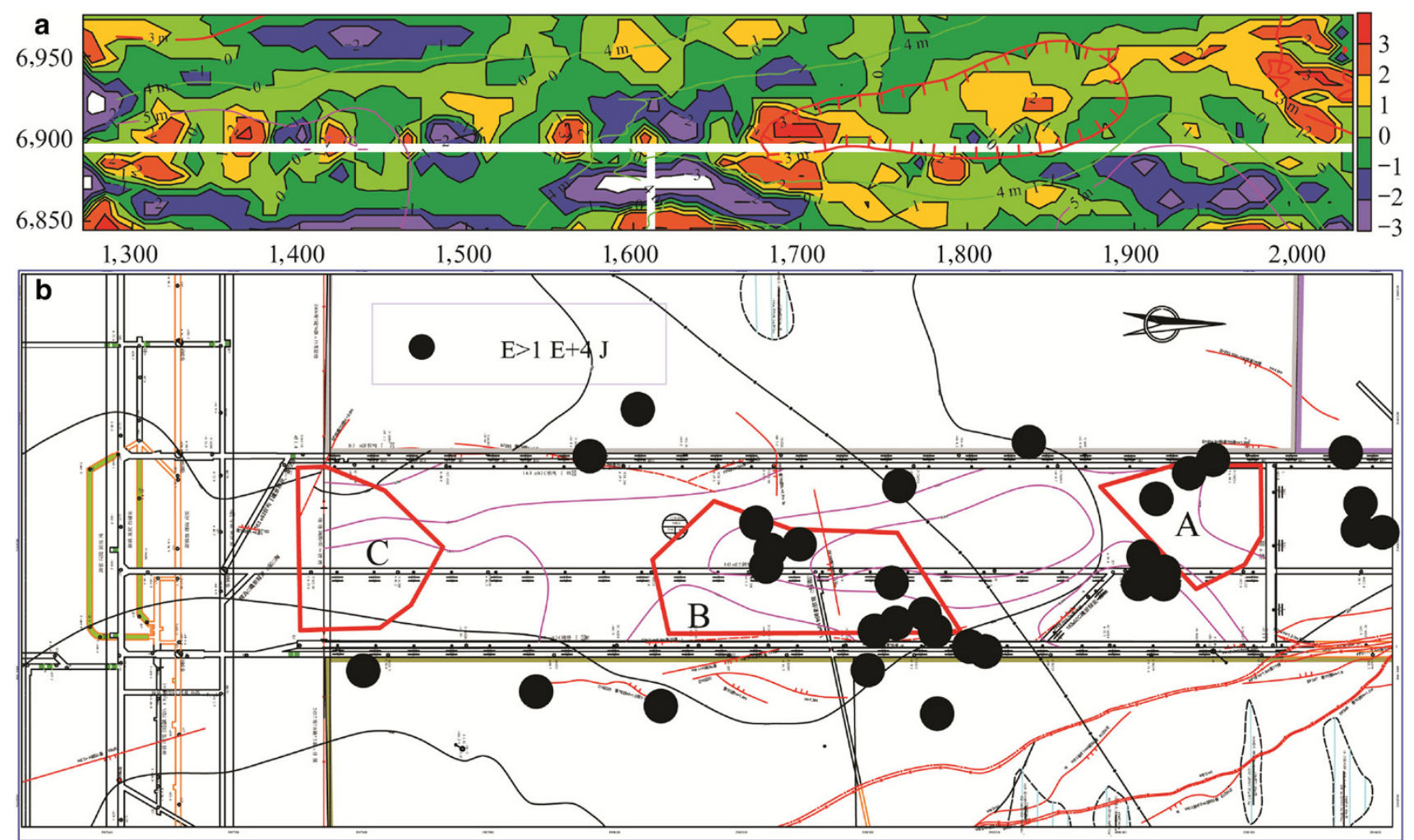

Fig. 3 a Inversed velocity anomaly distribution and b rockburst danger area classification and tremor source location of LW16302C

well as the power functional relationship between longitudinal wave velocity and coal rock stress (Gong 2010; Gong et al. 2012b). Dou et al. (2012), He et al. (2011) and Gong (2010) conducted detailed studies on the application of elastic wave CT technology in forecasting the burst danger region and established related evaluation indexes (velocity anomaly). Moreover, they successfully implemented this technology into No. 10 Pingdingshan Coal Mine, Yuejin Coal Mine, Xingcun Coal Mine, Jining No. 3 Coal Mine, Liangbaosi Coal Mine, and Wanglou Coal Mine etc. in China. They equipped this technology with a hardware device of GeoPen SE2404NT. Instead, the PASAT-M portable microseismic detection system was used by other researchers for this technology (Wang et al. 2012a).

Figure 3 shows the application effect of this technology on longwall face 16302C (LW16302C). According to the evaluation indexes, it is getable of three potential burst danger areas (A, B, and $\mathrm{C}$ ). The high wave velocities and velocity anomalies in the three areas signify that stresses are highly concentrated. Comparison on the tremor source (with energy higher than $10^{4} \mathrm{~J}$ ) distribution reveals that most of the mine tremors happen in areas A and B. According to rockburst theory, the mine tremor with higher energy level are more likely to develop rockburst and show more concentrated stress. It is visible that the potential burst danger areas forecasted using elastic wave CT technology are highly consisted with the microseismic monitoring results.

\subsection{EMR technology to monitor local dynamic stress}

EMR originates from the deformation and failure process of coal rocks. The mechanism of EMR induced by the deformation and failure of coal rocks has been studied in detail (Dou et al. 2001, 2002). Studies imply that the failure and deformation of coal rocks generating EMR is derived from the anisotropism of coal rocks and is attributed to the nonuniform deformation in coal rocks under stress effect. Dou et al. $(2001,2004)$ experimentally investigated the variation law of the EMR signals yielded in the uniaxial compression of coal rock samples and found that EMR intensity and pulse increased with the growing of the loading rate and deformation rate. Moreover, they concluded that EMR intensity lay below a certain value before the burst failure of coal rock samples, while sharply increased in case of burst failure. Wang et al. (2012b) studied the relationship of EMR emitted by various, uniaxially loaded, coal rock samples (coal, rock, roof-coal-floor composite) in their whole deformation and failure processes to the applied loads, and found that EMR signal was linearly related to the applied loads, 


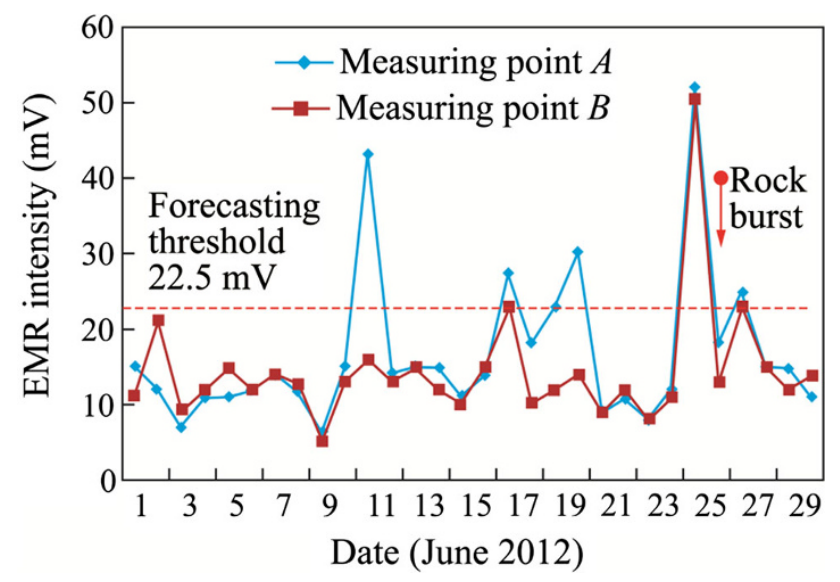

Fig. 4 Variation law of EMR intensity before and after rockburst

while the number of EMR pulses was a third power function of the applied loads. These studies indicate that EMR signal is capable of reflecting the stress (load) state, deformation and fracture strength, and internal stress state of coal rock mass. Basing on the studies above, the EMR forecasting criteria for rockburst danger degree was profoundly researched (Dou et al. 2002, 2004; Chen et al. 2008).

Figure 4 shows the variations of the EMR intensity in the tail gate of a longwall face before and after the rockburst on June 26, 2012. This rockburst showed a damage range of $45 \mathrm{~m}$ in the tail gate from the longwall face. The longwall face was conducted with circulating EMR monitoring each day on 20 points in the tail gate and head gate (ten for each) in front of the longwall face. The interval between two adjacent monitoring points is $20 \mathrm{~m}$. The EMR signals in this figure were valued as the mean of the maximum EMR intensity monitored every day. Monitoring data were sourced from point $A$ and point $B$ in the damage region of the tail gate, which were 200 and $220 \mathrm{~m}$ away from the open-off cut respectively. When the rockburst happens, the longwall face was $176.8 \mathrm{~m}$ away from the open-off cut. The longwall face was advanced by $1.6-2.4 \mathrm{~m}$ daily. The forecasting threshold of the EMR intensity of the longwall face was $22.5 \mathrm{mV}$. As shown in this figure, 10 days before the rockburst, the EMR intensity monitored on the two points was significantly abnormal, in specific, the EMR intensity was higher and exceeded or approached to the forecasting threshold. 5 days before the rockburst, it kept relatively low. On the day before the rockburst, the EMR intensity suddenly rose to an abnormally high value (the EMR intensities on point $\mathrm{A}$ and $\mathrm{B}$ both exceeds $50 \mathrm{mV}$, which is significantly higher than the forecasting threshold) and then the rockburst happened. The variation law above is similar to previous research results. It is obvious that EMR can be used to effectively forecast the rockburst.
3.4 Seismic wave CT technology to detect regional and local dynamic stress

Mining activities can induce mine tremor. The tomography using the seismic wave of mine tremor is called as seismic wave CT. Since the tremor source cannot be precontrolled, it is also called as passive CT. Seismic wave CT technology is a research fruit in recent years. At abroad, Luo et al. (2009) used the tremor signals triggered by the coal cutting of shearer as stimulating source and allocated receivers in the two roadways. Luxbacher et al. (2008) inverted the $\mathrm{P}$ wave velocity in the mining process using mine tremor as stimulating source and found that high-stress region was in good agreement with high wave velocity region. Lurka (2008) used passive CT technology to evaluate the danger degree of Coal mines in Poland such as Zabrze Bielszowice Coal Mine and pointed out that rockburst or strong mine tremor mainly happened in high wave velocity area or high gradient area of wave velocity. In China, based on microseismic monitoring system (currently supports SOS and ARAMIS M/E), Gong and other experts (Gong 2010; Gong et al. 2012a) systematically investigated the seismic wave CT model and its solving principle and method. Moreover, to improve the CT-inverting accuracy and reliability, they profoundly studied the optimization of microseismic location and network allocation, seismic wave selection and wave denoising etc., and put forward three parameters as the evaluation indexes of rockburst danger, namely wave velocity, wave velocity anomaly, and the gradient velocity anomaly. On this basis, they developed relatively perfect seismic wave CT technology, which improved the reliability of monitoring and forecasting of rockburst. At present, this technology has been applied to more than ten coal mines in China, including Yuejin Coal Mine, Xingcun Coal Mine, Xing' an Coal Mine, Junde Coal Mine, Fuli Coal Mine, Nanshan Coal Mine, Huating Coal Mine, Zhangxiaolou Coal Mine, and Jining No. 3 Coal Mine etc., and got favorable results.

Figure 5 shows the application effect of seismic wave CT technology on longwall face 25110 (LW25110). According to the wave velocity anomaly, it is getable of two potential burst danger areas $(B 1, B 2)$ and three depressurizing weakened areas $(R 1, R 2, R 3)$. Influenced by the abutment pressure, $B 1$ is an area frequently developing rockbursts. This area is about $100 \mathrm{~m}$ length in longwall advancing direction, which is basically consistent with the real influencing region of the abutment pressure on spot. $B 2$ is influenced by the remaining coal pillar of longwall face 25090. Because of the hang roof on the gob side, the internal stress of the coal pillar are highly concentrated. $R 1$ are $R 2$ are the depressurizing areas. In the two areas, coal rocks are weakened and stress levels are low. 


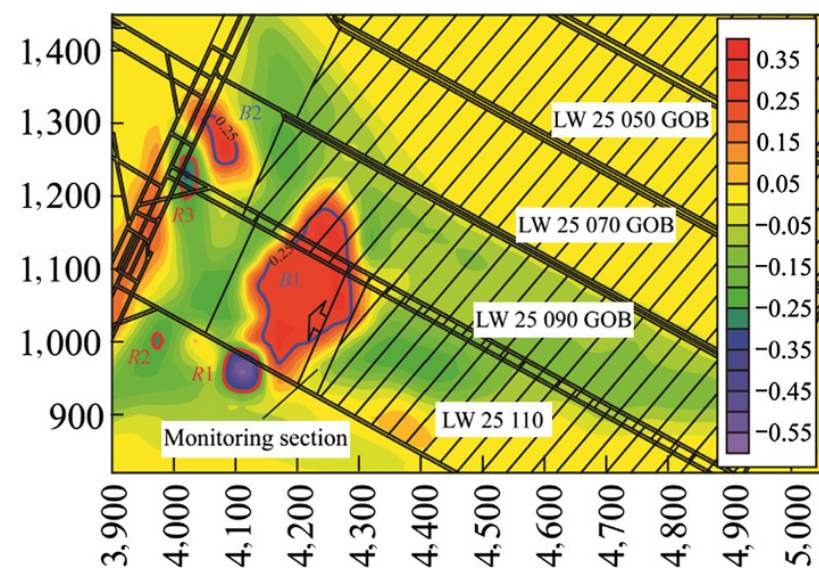

Fig. 5 Classification of rockburst danger area and weakened area of LW25110 based on the anomaly index

It is visible that the seismic wave CT technology is reliable to forecast rockburst danger areas.

\section{Controlling of rockburst}

\subsection{Intensity weakening theory}

Intensity weakening theory (Dou et al. 2005; Lu 2008) lays the theoretical basis for rockburst control of most coal mines with rockburst danger. It guides the controlling of rockburst from an angle of energy and considers that the occurrence of rockburst should firstly meet the condition which is that the elastic energy accumulated in coal rocks reaches and exceeds the critical elastic strain energy $U_{J}$ (the minimum strain energy accumulated in coal rocks when rockburst happens). In case of the elastic energy accumulation in the coal rocks being lower than the energy dissipation at random time point, the elastic energy saved in the coal rock continuously reduces and is increasingly lower than $U_{J}$. As a result, the rockburst danger becomes smaller. In case of the elastic energy accumulation in the coal rocks being larger than the energy dissipation at random time point, the elastic energy saved in the coal rock continuously increases to be equal to $U_{J}$. In this case, the energy stays at a critical state and any minor energy increase will induce a rockburst. Therefore, to prevent the rockburst, depressurizing measures are needed to artificially reduce the elastic energy accumulated in the coal rocks, as shown in Fig. 6. It should be noted that the elastic energy saved in the coal rocks can increase suddenly in case of hard roof breaking or mine tremors.

Intensity weakening technology is applicable to prevent rockburst in the simultaneously processes of mining (tunneling), monitoring, and controlling, that is, the theory is realized

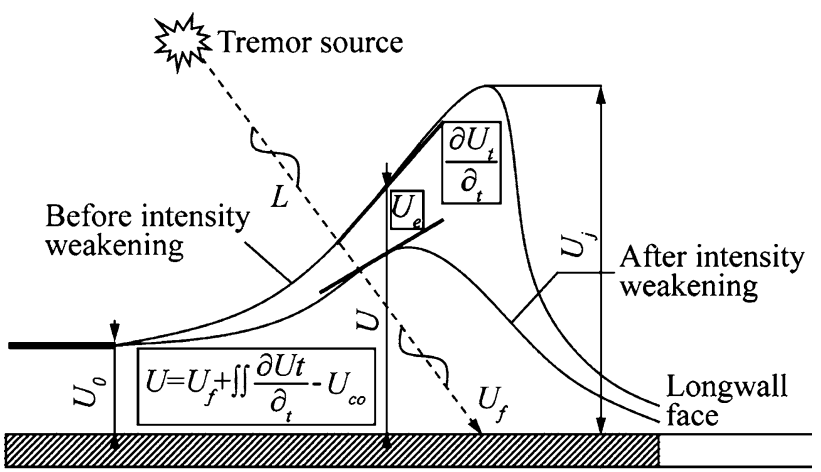

Fig. 6 Energy accumulation and energy dissipation before and after intensity weakening of coal rock mass

by a process of "longwall face advancing (tunneling) $\rightarrow$ rockburst danger monitoring $\rightarrow$ energy accumulating $\rightarrow$ taking pressure-releasing measures $\rightarrow$ energy dissipating $\rightarrow$ mining $\rightarrow$ re-monitoring $\rightarrow$...". It has three meanings: (1) in the burst danger area, the burst danger degree can be reduced by decreasing the intensity and burst tendency of coal rocks by means of cracking and loosening coal rocks; (2) after the intensity of the coal rocks is weakened, the peak stress area is transformed to the depth of the coal rocks and the stress concentrating degree is decreased; (3) by taking certain pressure-releasing measures, the damage intensity can be reduced when rockburst occurs.

\subsection{Strong-soft-strong structure effect for roadway control}

The latest statistical data (Pan et al. 2013) show that $87 \%$ of the rockbursts occurred in roadways in China. Comparing with the $72.6 \%$ in previous statistics (Dou and $\mathrm{He}$ 2001), this proportion saw certain increase. Therefore, rockburst researches should be focused on the prevention and control of roadway damage. The strong-soft-strong structure provides favorable guidance for the prevention of roadway rockburst. This structure is based on the recognition on the burst failure mechanism of roadway, that is, the propagation and disturbance of seismic stress wave generated by mine tremors is a key factor for the burst failure of roadway. As the total stress (due to the superposition of the seismic stress wave and the stress field of roadway surrounding) surpasses the bearing limit of surrounding supports, roadway rockburst is prone to be induced. The strong-soft-strong structure is proposed by Gao et al. (Gao 2006; Gao et al. 2008) and has been researched profoundly and comprehensively.

Figure 7 shows the strong-soft-strong structure. From far to near, it shows the large structure for burst-transmitting, the middle structure for energy and wave-dissipating, and the small structure for supporting and protection in 


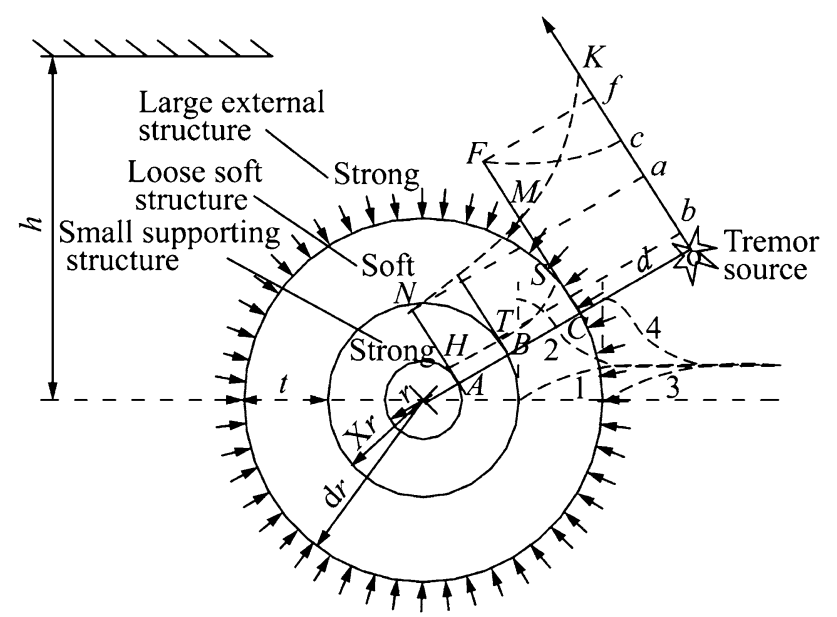

Fig. 7 Strong-soft-strong structure model of the roadway surrounding subjected to rockburst

turn. The first one presented relatively complete and highly intensive surrounding structure and is an externally strong structure; the second one is a soft structure with loose and broken surrounding rocks; the third structure is a internally strong structure that needs strengthened supports to keep its stability. The middle soft structure makes the seismic stresses transformed from the large structure be reflected on or transmitted through the surfaces between the soft and strong structures. Part of the stress wave is reflected into the externally strong structure, while part of the stress wave is transmitted into the soft structure. The stress waves' amplitudes are weakened after being transmitted into the soft structure. Moreover, after being dissipated and absorbed in the internal of soft structure, the stress intensity is further attenuated. In this way, the stress transmitted to the internally strong small structure is greatly reduced. Since the superposed stress is lower than the limit bearing strength of the small roadway support structure, the stability of the small structure is ensured. Strong-soft-strong structure can effectively attenuate or absorb the seismic stress waves and keep the roadway in a low stress field region. Furthermore, in case of no seismic wave, this structure transformed the high stress of the roadway surrounding to the depth. Such transformation is beneficial to stabilize the roadway in deep high stress environment.

\subsection{High-pressured directional hydraulic fracturing technology to pre-split hard roofs}

Hard and thick roof acts as an important inducement for rockburst. At present, hard and thick roof is mainly controlled by water softening or blasting to achieve roof weakening. However, the two methods have their own disadvantages: water softening depends on the hydroscopicity of coal rocks, while blasting is work-intensive and

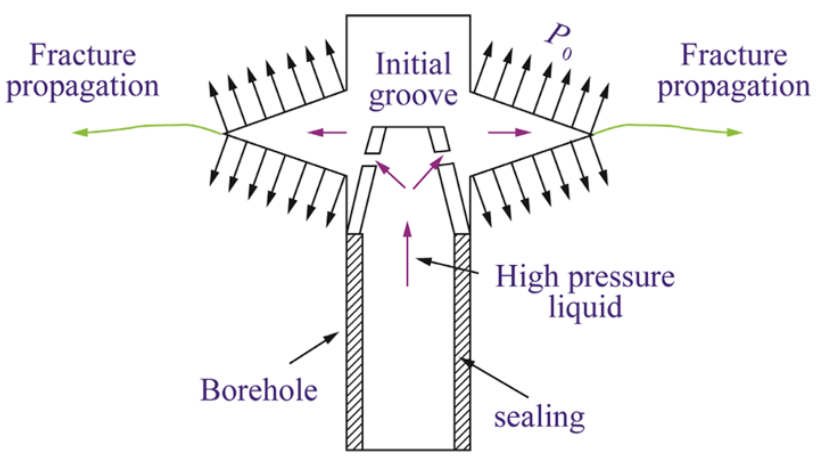

Fig. 8 Essence of directional fracturing

unsafe. As a novel technology for controlling hard and thick roofs, high-pressured directional hydraulic fracturing technology is time-saving, labor-saving, safe, and effective. Although it is still on the trial stage at present, this technology shows broad application prospect. He and Dou et al. (Du 2010; He et al. 2012) conducted detailed analysis on the burst resisting mechanism by hard roof fracturing, as well as the crack expanding mechanism and related influencing factors concerning this technology. Furthermore, they applied this technology into the industrial tests.

Figure 8 shows that the essence of directional fracturing is the generation of a spatially oriented fracture in the rock mass and under the impact of high pressure liquid injected into the borehole, the cracks propagate from the tips of the oriented fracture thereby dividing the rock layers into blocks or plates with determined sizes and forms. Such a process is owing to the generation of the so-called initial groove with exactly spatial orientation in the borehole surroundings. This initial groove delimits the direction of fracture propagation and its rise is induced by the high pressure liquid. Both the integrity and strength of hard roof are weakened after fractured, as a result the sudden roof falling with large area is avoided and the rock burst danger reduced ultimately.

Directional fracturing technology was applied at LW5307 in Jining No. 3 coal mine. The sandstone main roof was $16.77-41.12 \mathrm{~m}$ thick ( $28 \mathrm{~m}$ in average) with a tensile strength of 8-10 MPa, and immediately laid above on the coal seam. Mining tremors and rock bursts occurred frequently dominantly due to the caving of the thick hard main roof with a hanging length over $50 \mathrm{~m}$. Figure 9 shows the layout of the boreholes, which were pre-drilled into the roadway roof by geological drilling rig. The diameter and depth of the boreholes were $46-48 \mathrm{~mm}$ and $10-20 \mathrm{~m}$, respectively. Then a sharp wedge-shaped initial groove (with a diameter of approximately $133 \mathrm{~mm}$ ) was notched at the bottom of the borehole using a special cutting machine. At last, the borehole was sealed using Bimbar-4 seals and 


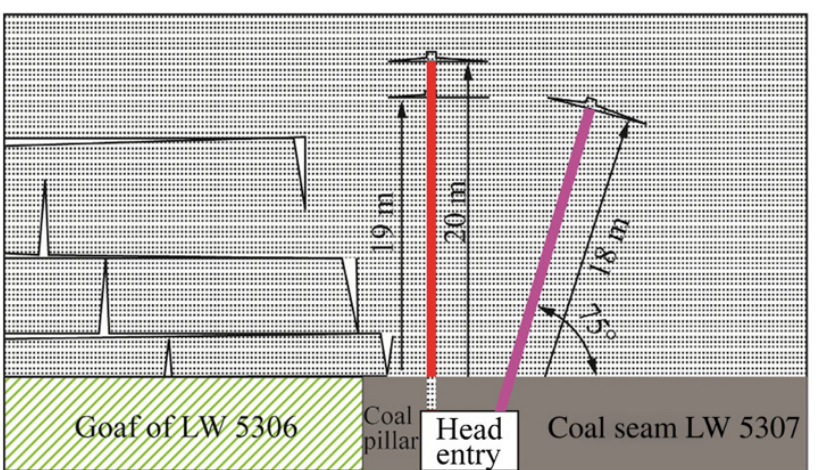

Fig. 9 Layout of directional hydraulic fracturing holes at LW5307

high-pressure liquid was injected into the groove. After directional hydraulic fracturing was put into effect, no dynamic effects were encountered, which indicated that directional hydraulic fracturing of the main roof can reduce the local stress and greatly diminish dynamic load.

\subsection{Support system against dynamic and static stresses}

Rockburst ultimately leads to the sudden violent dynamic failures of roadway or coalface, of which $87 \%$ (Pan et al. 2013) occurs in the roadway. Therefore, it is of direct significance for the control of rockburst by inhibiting the failure of roadway and coalface through support means. As for rockburst-resisting roadways, the support system should be capable of resisting high burst dynamics, providing appropriate pressure yielding deformation, and owning a flexibility that can play a buffering and energy-absorbing role (Gao et al. 2009). Bolt has become a reasonable supporting mean due to its initiative, pressure yielding ability, energy absorbing ability, and the capability in utilizing the bearing capacity of surrounding rocks (Gao et al. 2009; He et al. 2010). However, bolt support technology can only resist the rockburst under certain intensity. As for highenergy rockburst, energy absorbing materials are needed to consume part of the tremor energy to stabilize the support system (Lv et al. 2011). On this basis, Pan and Lv et al. (Pan et al. 2011; Lv and Pan 2012) proposed a structure model of rigid-flexible energy-absorbing support which was composed of surrounding rocks, energy absorbing materials, and steel bracket (rigid-flexible-rigid). In essence, the model is similar to the strong-soft-strong structure model (Gao et al. 2008). The surrounding rocks, energy absorbing materials, and steel bracket are equivalent to the externally strong large structure, middle soft structure, internally strong small structure respectively. Theoretically basing on the model above, the rigid-flexible energy-absorbing support system (Liu et al. 2013) was developed. It is a three-level support system composed of three parts, namely, the bolt-mesh-cable support, the
O-type roof support made of energy absorbing materials and U-type steels (simply called as O-type roof support), and the rigid burst-resisting bracket. The energy absorbing materials lay between the bolt-mesh-cable support and O-type roof support. This support system was implemented in Yuejin Coal Mine of Henan Dayou Energy Co., Ltd., China, and effectively avoided roadway damages, equipment damages, and casualties when high-energy rockburst occurred.

\section{Development prospect of rockburst control}

There are various rockburst theories and forecasting, monitoring, preventing, and controlling methods, which is attributed to that the causing essence of rockburst has not been clear. Researches about rockburst in China may develop toward the following aspects.

(1) The further investigation on the mechanism of rockburst. It includes the following aspects: profoundly researching the mechanism of the rockburst induced by static and dynamic stresses superposition; specifically exploring the critical stress and the proportions of the static and dynamic stresses in the superposed total stress under different conditions for rockburst occurrence; exploring the tremor-induced dynamic stress yielded by the overlying strata in the gob area due to the secondary or repeated disturbance of the mining activities around; developing quantitative researches by combining the mechanism of the rockburst induced by static and dynamic stresses superposition with the burst failure mechanism of the roadway surroundings; studying the influences of mining disturbances on peripheral roadways; studying the mechanism, prevention theory, controlling technology of the rockburst in coal mines of more than one thousand meters deep; studying the stress distribution characteristics in the surrounding rocks near large tectonic areas and their influences on the rockburst. Through these studies, it is able to get the burst failure criteria of surrounding rocks with higher practical engineering value to more effectively guide the prevention and control of rockburst in field.

(2) The further research on monitoring, forecasting, and controlling of rockburst. There are numerous measures, technologies and methods for monitoring, forecasting, and controlling rockbursts. Unfortunately, it is lacked of rules and guidance theories for the application of various monitoring devices. Generally, coal mines with high rockburst danger are governed comprehensively using various monitoring 
methods and controlling measures, while fail to conduct targeted studies on the rockburst mechanism. Therefore, the forecasting results obtained using various monitoring data are inconsistent or even opposite and thus inapplicable to reasonably evaluate the controlling effect of various controlling measures. In future, the using rule and ranges of various monitoring methods should be studied in detail. The application of monitoring, forecasting, and controlling methods against rockburst should be based on the analysis of the rockburst mechanism. It is expected to improve the scientificity by exploring the main static and dynamic stress factors influencing rockburst, the reasonable monitoring plans for static and dynamic stresses, and reasonable controlling methods against the main controlling factors of rockburst.

Acknowledgments The research was supported by the National Natural Science Foundation of China (51174285, 51104150), the Research and Innovation Project for College Graduates of Jiangsu Province (CXZZ12_0949), the National Twelfth-Five Year Research Program of China (2012BAK09B01).

Open Access This article is distributed under the terms of the Creative Commons Attribution License which permits any use, distribution, and reproduction in any medium, provided the original author(s) and the source are credited.

\section{References}

Brady BHG, Brown ET (2004) Rock mechanics for underground mining, 3rd edn. Kluwer Academic Publisher, Dordrecht

Chen GX, Dou LM, Cao AY, Li ZH (2008) Assessment of rock burst danger and application on electromagnetic emission method. J China Coal Soc 33(8):866-870 (in Chinese)

Cook NCG (1965) A note on rock bursts considered as a problem of stability. J S Afr Inst Min Metall 65:437-446

Dou LM, He XQ (2001) Theory and technology of rock burst prevention. China University of Mining and Technology Press, Xuzhou (in Chinese)

Dou LM, He XQ (2007) Technique of classification forecasting rock burst in coal mines. J China Univ Min Technol 36(6):717-722 (in Chinese)

Dou LM, He XQ, Wang EY, Gu DZ (2001) Electromagetic emissions in rock and coal burst failures. J Tsinghua Univ (Sci Technol) 41(12):86-88 (in Chinese)

Dou LM, Cao QW, He XQ, Wang EY (2002) EME monitoring technique of rock burst. Ground Press Strata Control. 19(4):89-91 (in Chinese)

Dou LM, He XQ, Wang EY (2004) Electromagnetic emission technique of monitoring rock burst and its application. J China Coal Soc 29(4):396-399 (in Chinese)

Dou LM, Lu CP, Mu ZL, Qin YH, Yao JM (2005) Intensity weakening theory for rockburst and its application. J China Coal Soc 30(6):690-694 (in Chinese)

Dou LM, Chen TJ, Gong SY, He H, Zhang SB (2012) Rockburst hazard determination by using computed tomography technology in deep workface. Saf Sci 50(4):736-740
Du TT (2010) Study on mechanism of rockburst prevention by hard roof directional hydraulic fracture. China University of Mining and Technology, Xuzhou (in Chinese)

Gao MS (2006) Study on the strong-soft-strong structure control mechanism of roadway subjected to rock burst. China University of Mining and Technology, Xuzhou (in Chinese)

Gao MS, Dou LM, Zhang N, Wang K, Zheng BS (2008) Strong-softstrong mechanical model for controlling roadway surrounding rock subjected to rock burst and its application. Rock Soil Mech 29(2):359-364 (in Chinese)

Gao MS, Dou LM, Yan RL, Han CL, Guo YS (2009) Prevention mechanism of roadway supported by bolt-mesh subjected to rock burst and degree calculation. J Min Saf Eng 26(4):402-406 (in Chinese)

Gong SY (2010) Research and application of using mine tremor velocity tomography to forecast rockburst danger in coal mine. China University of Mining and Technology, Xuzhou (in Chinese)

Gong SY, Dou LM, Xu XJ, He J, Lu CP, He H (2012a) Experimental study on the correlation between stress and P-wave velocity for burst tendency coal-rock samples. J Min Saf Eng 29(1):67-71 (in Chinese)

Gong SY, Dou LM, Ma XP, Mu ZL, Lu CP (2012b) Optimization algorithm of network configuration for improving location accuracy of microseism in coal mine. Chin J Rock Mech Eng 31(1):8-17 (in Chinese)

Gu ST, Wang CQ, Jiang BY, Tan YL, Li NN (2012) Field test of rock burst danger based on drilling pulverized coal parameters. Disaster Adv 5(4):237-240

He J (2013) Research of mining dynamic loading effect and its induced rock burst in coal mine. China University of Mining and Technology, Xuzhou (in Chinese)

He H, Dou LM, Gong SY, Wang LL, Gao MS, Zhang XF (2010) Mechanism of rockburst prevention and supporting control technology in roadways. J Min Saf Eng 27(1):40-44 (in Chinese)

He H, Dou L, Li X, Qiao Q, Chen T, Gong S (2011) Active velocity tomography for assessing rock burst hazards in a kilometer deep mine. Min Sci Technol 21(5):673-676

He H, Dou LM, Fan J, Du TT, Sun XL (2012) Deep-hole directional fracturing of thick hard roof for rockburst prevention. Tunn Undergr Space Technol 32:34-43

Ju WJ, Pan JF (2012) Status and prospect of rock-burst monitoring and alarm technology in Chinese coal mine. Coal Min Technol 17(6): 1-5 (in Chinese)

Kidybiński A (1981) Bursting liability indices of coal. Int J Rock Mech Min Sci Geomech Abstr 18(4):295-304

Li YS (1985) Rockburst mechanism and its preliminary application. J China Inst Min Technol 3:42-48 (in Chinese)

Liu J, Ouyang ZH, Qi QX, Zhao SK, Li XL (2013) Rigid-flexibility integrated energy absorption support technology applied in deep mine with pressure bumping. Coal Sci Technol 41(6):17-20 (in Chinese)

Lu CP (2008) Intensity weakening theory for rockburst of compound coal-rock and its application. China University of Mining and Technology, Xuzhou (in Chinese)

Luo X, King A, Van de Werken M (2009) Tomographic imaging of rock conditions ahead of mining using the shearer as a seismic Source-A feasibility study. IEEE Trans Geosci Remote Sens 47(11):3671-3678

Lurka A (2008) Location of high seismic activity zones and seismic hazard assessment in Zabrze Bielszowice coal mine using passive tomography. J China Univ Min Technol 18(2):177-181

Luxbacher K, Westman E, Swanson P, Karfakis M (2008) Threedimensional time-lapse velocity tomography of an underground longwall panel. Int J Rock Mech Min Sci 45(4):478-485

Lv XF, Pan YS (2012) Theoretical analysis and experimental research on rockburst prevention mechanism of rigid-flexible-rigid 
supporting structure. Chin J Rock Mech Eng 31(1):52-59 (in Chinese)

Lv XF, Pan YS, Li ZH, Dai SH (2011) Study on deformation and failure of roadway of rock bolting under impact loading. J China Coal Soc 36(1):24-28 (in Chinese)

Pan YS, Lv XF, Li ZH (2011) The model of energy-absorbing coupling support and its application in rock burst roadway. J Min Saf Eng 28(1):6-10 (in Chinese)

Pan JF, Mao DB, Lan H, Wang SW, Qi QX (2013) Study status and prospects of mine pressure bumping control technology in China. Coal Sci Technol 41(6):21-25 (in Chinese)

Petukhov IM, Linkov AM (1979) The theory of post-failure deformations and the problem of stability in rock mechanics. Int J Rock Mech Min Sci Geomech Abstr 16(2):57-76
Singh SP (1988) Burst energy release index. Rock Mech Rock Eng 21(2):149-155

Wang WD, Zhao J, Hu JW (1996) Elastic wave CT technique and its application. Coal Geol Explor 24(5):59-63 (in Chinese)

Wang SW, Mao DB, Du TT, Chen FB, Feng MH (2012a) Rockburst hazard evaluation model based on seismic CT technology. J China Coal Soc 37(S1):1-6 (in Chinese)

Wang EY, He XQ, Liu XF, Xu WQ (2012b) Comprehensive monitoring technique based on electromagnetic radiation and its applications to mine pressure. Saf Sci 50(4):885-893

Zhang MT (1987) Instability theory and mathematical model for coal/rock bursts. Chin J Rock Mech Eng 6(3):197-204 (in Chinese) 